\title{
农业工程中农业机械化发展的现状及对策分析
}

邢俊

达拉特旗农业综合开发办公室

DOI:10.32629/as.v3i1.1754

[摘要] 农业是我国的立国之本,作为一个农业大国,面对人口不断增长的粮食需求,推动农业现代化发展是必然选择。在农业现代化进程中,农 业机械化发展趋势明显,借助先进的农机设备和技术进行规模化生产, 可以有效提升农业生产效率和效益, 减少人工劳动强度,创造更加可观的经 济效益同时, 满足大量人口的粮食需求。但是,部分地区的农业机械化发展速度滞后,无论是投入还是政策扶持都存在很大的不足,极大的影响到 农业实际生产中的问题。基于此, 本文就农业工程中农业机械化发展现状着重探究,针对其中的不足多维度分析, 提出合理有效的应对措施,推动 农业现代化发展。

[关键词] 农业机械化; 农业工程；农业现代化；农机设备；农业生产

农业现代化进程不断加快, 农业机械化作为一项重要内容, 为新时期 的农业发展带来了新的活力和动力。尤其是当前全球经济增长下,农业科 技手段不断发展和创新, 涌现出很多新式的农业机械设备和技术, 为农业 机械化发展提供坚实保障的同时, 也可以大大提升农业生产效率, 满足人 口不断增长下的粮食需求。在农业发展中, 扎稳脚跟, 不断清扫障碍, 把握 新形势, 合理规划和发展, 提出合理有效的优化措施谋求可持续发展。故此, 加强农业工程中农业机械化发展内容研究, 立足现状, 提出优化措施予以 实践, 以求提升农业生产技术水平, 推动农业现代化发展。

\section{1 农业机械化发展趋势}

农业机械是现代农业生产和发展的基础保障, 通过农业机械设备和技 术的引进, 可以改善传统农业生产作业形式, 形成更具现代化的产业形式, 依托于农业机械来提升整体的装备生产, 改良农业生产条件, 提升农业产 业发展效率, 对于农业整体效益发展具有积极作用。我国作为一个农业大 国, 农作物管理分散, 需要进一步强化农业经营管理水平和技术水平, 具备 更强的生产力, 以此来推动农业机械化发展 ${ }^{[1]}$ 。

结合当前农业发展现状来看, 以小农形式为主, 机械化技术水平不 高, 普及范围狭窄, 甚至很多农户对农业机械化存在抵触情绪, 只有将分 散农户与农业机械形成有机联系的整体, 才可以充分发挥农机设备的作 用, 提升农业机械化水平。农业机械化, 是提升农业整体经济效益的关键 所在, 需要不断增加技术投入力度, 形成完善的技术管理体系, 才可以研 究出更多新型机械化技术, 推动农业跨越式发展 ${ }^{\left[{ }^{[2]}\right.}$ 。提升农业机械化技 术水平, 满足现代农业生产需要, 改良农机装备, 实现农业高效、安全和 节能发展。

\section{2 农业工程中农业机械化的发展现状剖析}

我国是一个农业大国, 推动农业机械化是一项系统工程, 并非一朝一 夕即可实现, 尤其是很多区域的农业生产水平、地理条件和气候环境有所 差异, 对于农业机械化发展提出了不同层次的要求。所以, 现有的农业工程 中, 农业机械化发展存在很多的问题, 表现为地域发展失衡、发展方向偏 差、基础设施设备不完善。

2. 1 地域发展失衡问题严峻

我国地域广阔, 不同地区地质条件差异显著, 尤其是气候条件、生态环 境和土壤条件都存在很大的差异, 农业生态环境的营造, 需要针对不同区 域特点合理配置资源, 灵活运用机械设备, 提升农业生产水平 ${ }^{[3]}$ 。但是, 不 同区域之间的经济水平和地质条件存在一定差异, 致使农业机械化推广还 处于起步阶段, 地理发展失衡的问题, 导致很多区域无法灵活运用机械设 备, 自动化水平不高。部分区域的土地资源利用效率不高, 劳动力数量贾乏,
大力推动农业机械化是必然选择, 在提升农业机械化水平的同时, 赋予 农业持久发展动力。结合相关数据研究了解到, 沿海区域经济发达, 农民 收入水平较高, 多是由于农机设备的广泛应用, 大大提升了区域的农业 经济水平 ${ }^{[4]}$ 。相较于沿海区域, 懂不区域的农业机械化为中等, 西部地区 农业机械化水平落后, 极大的影响到农业生产效率的提升。总体来看, 我 国的农业机械化还处于初级阶段, 区域之间的农机发展水平差异明显, 影响因素多样, 在沿海区域农机设备广泛应用, 农民收入水平大幅度升 高, 而东部地区的农业机械设备的应用, 仅仅在耕地面积 $32 \%$ 左右, 农业 机械化水平一般, 西部地区很少运用农机设备, 此种差异性问题, 需要进 一步改进和完善 ${ }^{[5]}$ 。

2. 2 农业发展方向存在偏差、不明确的问题

结合我国当前农业发展历程来看, 小型的农业机械设备呈现良好的 发展形势, 农业机械价格便宜, 推广和应用成果良好, 但是大中型机械设 备的推广使用难度较大, 受影响因素多样, 多是由于价格和区域差异等 因素影响, 但是, 大中型农业机械设备对农业经济发展所起到的作用鲜 明, 可以更好的满足我国农业现代化发展需求。地区差异, 农业机械化发 展方向同样存在差异, 部分区域适合小型农用机械设备进行生产活动, 部分区域则适合大中型机械设备大规模耕地, 这就需要各级政府充分发 挥主导作用, 提供政策扶持和指导, 契合区域实际情况编制合理措施, 有 侧重性的发展 ${ }^{[6]}$ 。

结合不同区域农机设备使用情况, 大中型农业机械设备通常是农户 集体购买, 农机设备利用效率较高, 在提升农业生产效率的同时, 可以带 来更加可观的经济效益。增加农业机械经济效益, 结合具体使用情况定 期检修和维护, 对于其中存在的不足和缺陷及时改进, 协调生产需要, 规 避农机设备实际应用中的矛盾冲突。小型农机设备发展速度快, 大中型 农机设备的应用, 需要充分契合农业现代化发展需要, 结合不同区域具 体情况灵活选用农机设备, 避免出现发展方向偏差的问题。我国当前的 农民收入水平远远落后于发达国家, 农业生产倾向于劳动力密集型生产 模式, 农业机械设备的应用受限程度不同, 导致最终带来的经济效益存 在很大的差异 ${ }^{[7]}$ 。作为农业大国, 推动农业现代化发展, 应致力于技术研 发, 增加投入力度, 完善配套的基础设施, 创新发展思路, 实现农业机械 化良性发展。

\section{3 我国农业工程中推动农业机械化发展的有效途径}

3. 1 契合国情优化地区产业结构

针对我国农业地域发展失衡的问题, 如何推动农业机械化良性化发展, 应该充分契合国情, 结合不同区域的经济发展水平和农业发展情况, 针对 
性的引进农机设备, 制定合理的措施针对性干预控制, 提升农业机械化水 平。我国农业机械化在长期发展中, 逐渐取得了可观的成果, 在引进先进的 农业机械设备同时, 推动不同区域的产业结构, 扩大农业机械化推广宣传 力度, 为后续相关工作展开营造可靠的环境 ${ }^{[8]}$ 。故此, 农业机械化发展, 结 合不同区域的地质条件和生态环境优化产业结构, 如西北区域农业机械化 水平不高, 在政府主导下增加投入力度, 引进先进技术手段来推动农业机 械化生产, 改良生态环境, 减少区域农业发展差异问题。经济发展水平较高 的区域, 农业机械设备得到了大规模的推广和应用, 在政府主导下优化产 业结构, 加快农业机械化发展进程。

\section{2增加投入来完善农业机械化基础设施}

沿海区域的农业机械化水平持续提升, 已经达到了一定的层次, 面对 不断扩大的农业机械设备应用范围, 应该进一步增加投入力度完善配套的 农业机械化基础设施, 在政府引导和扶持下, 调动农户购置农机设备的积 极性, 提升区域的农业机械化水平 ${ }^{[9]}$ 。但是, 部分地区的农机利用率不高, 主要是由于农业机械设备长时间高强度使用, 导致设备磨损、老化严重, 但是缺少专业维修人员, 致使农业机械设备的合理运用还有待进一步改进, 在政府引导下完善区域基础设施, 提升农业机械化水平的同时, 朝着良性 方向发展。

需要注意的是, 农业机械设备运行原理复杂, 设备故障检修需要专业 人员负责, 及时找到故障位置和原因, 才可以针对性的检修和维护机械设 备, 提升农业机械化效率的同时, 促进农户收入增长。在使用农业机械化设 备时, 可以不断增加资金投入力度来改造设备, 提升农业机械设备性能, 提 升农业机械化生产水平, 带来更大的经济效益。

3. 转变农民思维同时大力推广农机设备

由于很多地区的农民文化素质水平不高, 对农业机械化认知不足, 导 致即便购置了农业机械设备, 却存在不合理运用现象。这就需要加快相关 技术推广和应用, 做好农业机械设备的检修和保养, 确保机械设备原有作 用得到充分发挥。扩大教育宣传力度同时, 组织农民加快机械设备使用方 式的学习和了解, 了解如何维护和检修农机设备, 可以派遣农业机械设备
专业人才现场指导操作方法, 帮助农民掌握正确的方法, 在农业生产中灵 活运用。各级政府充分发挥自身引导作用, 帮助农民转变陈旧、滞后的思 维模式, 灵活运用先进技术手段和设备, 提升农业生产效率, 推动农业现代 化发展的同时, 创造更大的经济效益和社会效益。

\section{4 结论}

综上所述, 我国是一个农业大国, 面对农业现代化发展要求, 应增加资 金投入力度来购置先进的农业机械设备和技术, 尊重区域差异特性, 推动 农业机械设备自动化和智能化发展, 只有这样, 才能推动我国农业健康持 续发展。

\section{[参考文献]}

[1]马治国.农业机械化技术在农业发展中的作用和推广策略[J].河南 农业,2019,22(29):37-38。

[2]程宁宁.农机现代化助力乡村振兴——访江西省农业科学院农业 工程研究所所长、研究员吴罗发[J].农村百事通,2019,12(19):4-8.

[3]黄凰,吴昭雄.稻油轮作系统农业机械化生产工程模式构建与特征 分析[J].中国农机化学报,2019,40(01):162-167.

[4]方永昌.农业工程中农业机械化发展的现状及对策分析[J].农民致 富之友,2018,23(02):193.

[5]董振武.社会主义核心价值观视角下农业机械化发展策略[J].南方 农机,2017,48(24):177.

[6]陈小林,郡铁智.达州市达川区农业机械化发展存在的问题及建议 [J].乡村科技,2017,22(12):86-87.

[7]安静.农业工程中农业机械化发展的现状及对策分析[J].河北农 机,2016,31(06):22.

[8]赵琨.农业机械化发展对中国农业经济发展方式转变的影响研究 [D]. 黑龙江八一农圼大学,2014.

[9]彭朝威.浅谈科学发展乡镇农业机械化的措施及对策[J].农业与技 术,2013,33(10):56+118. 